\title{
USE OF BPM TO REDESIGN THE CONTAINER HANDLING PROCESS: A BRAZILIAN RETROPORTUARY TERMINAL CASE
}

\author{
André Andrade Longaray \\ Federal University of Rio Grande, Brazil \\ E-mail: longaray@yahoo.com.br \\ Paulo Roberto Munhoz \\ Federal University of Rio Grande, Brazil \\ E-mail: pamunhoz@terra.com.br \\ Alexandre Simão Albino \\ Federal University of Rio Grande, Brazil \\ E-mail: simao.alexandre@yahoo.com.br \\ Tiago Machado Castelli \\ Federal University of Rio Grande, Brazil \\ E-mail: tiagorip@gmail.com \\ Submission: 09/02/2015 \\ Revision: 20/02/2015 \\ Accept: 21/03/2015
}

\section{ABSTRACT}

This paper describes a proposal to redesign the containers handling process in a Brazilian retroportuary terminal using the Business Process Management (BPM) methodology. It employs applied research utilised through the different stages of a case study, and embodies the various aspects that influence the implementation of the internal handling process of containers in the concerned organisation. The mapping of the process allowed for a better understanding of the activity flow in the study. The new processes were laid out and redesigned. Their analysis displayed a considerable $43 \%$ reduction in container handling compared to the current process. Evaluation of the gathered data at the end of the study showed that the proposed redesigning of processes provided the organisation under study with the possibility of major improvements, which had a significant positive impact on the robustness, dynamics, and overall understanding of its business activities. 
INDEPENDENT JOURNAL OF MANAGEMENT \& PRODUCTION (IJM\&P)

http://www.ijmp.jor.br

v. 6 , n. 3, July - September 2015

ISSN: 2236-269X

DOI: 10.14807/ijmp.v6i3.294

Keywords: Container Handling; Business Process Management; Retroportuary Terminals

\section{INTRODUCTION}

Brazil's participation in international trade has been growing every year, especially in the areas of beef, pork, and chicken production. Consequently, the position of Rio Grande do Sul as one of the main producers and exporters of chicken in Brazil has drawn attention to the need for storage and transportation infrastructure that can meet the growing demand for export products. The export meat is transported by means of refrigerated containers, where the load is wrapped and shipped from the source (producer) to the final destination (external customer) in a controlled environment, which can ensure the delivery of the product in accordance with health requirements and customer preferences.

The Port of Rio Grande/RS is the only port in the state authorised to store and ship refrigerated and frozen cargo; thus, the entire production flows through that port. In addition to this, there is a need for an inventory of empty refrigerated containers to meet the demands of exporters - another essential component of the export process. The terminals that provide this service, referred to as retroportuary terminals, are held by private companies that operate outside the port area and are managed through concessions controlled by the Federal Revenue Service. At these terminals, containers and/or imported goods, or goods for export, are stored for inspection purposes.

The services provided by the retroportuary terminals at the Port of Rio Grande are determined by agreements within the companies that own the containers and the retroportuary terminals whose main services are the shipping of these containers to the storage areas in their facilities, where they undergo inspection processes, repairs, cleaning, and tests until they are made available to the export companies.

Considering all of the above, as a strategy to create a competitive advantage, more efficient and effective processes could be pursued, with a focus on increasing productivity, enhancing profitability ratios, and creating value for customers. In order to do this, there are various methodologies to improve the processes that are currently being used, such as the system of Business Process Management (BPM). 
INDEPENDENT JOURNAL OF MANAGEMENT \& PRODUCTION (IJM\&P)

http://www.ijmp.jor.br

v. 6, n. 3, July - September 2015

ISSN: 2236-269X

DOI: 10.14807/ijmp.v6i3.294

That being said, the guiding question of this research is, 'How can the steps for redesigning the container handling process at a retroportuary terminal be developed using the BPM method?'

Hence, the objective of this article is to describe a proposal that uses the BPM methodology to redesign the handling of the container process for a retroportuary terminal.

The manuscript is divided into five sections. Section two presents the theoretical basis for the study, which deals with the theme of handling containers and BPM. Section 3 presents the methodology used in the research, with respect to its nature, purpose, and approach. Section 4 lists in detail the steps undertaken in the case study. Finally, Section 5 presents a summary of the research conducted.

\section{THEORETICAL FRAMEWORK}

This section presents the theory that underlies this study. It discusses the 'practices and strategies of container handling' and the 'business process management' technique.

\subsection{Container Handling - Practices and Strategies}

The current decade foresees a considerable growth in container shipments across the world and, with it, an expanding need for optimizing the processes involved - namely, the handling of containers. Academic interests, as well as case reports, are constantly evolving from both strategic and operational perspectives (VACCA; et al., 2010).

From the strategic perspective, Stahlbock and Voß (2008) developed a study that provides the current state of the art container terminal operations and container handling. The authors analyzed the processes of vertical and integrated container operations, as well as their advantages and disadvantages. Notteboom (2002) discussed the changes that have occurred in recent years in the handling of containers in Europe. The author established an overview of the new dynamics between port terminals and logistics operators.

Theofanis and Boile (2009) examined the logistics of maritime containers on a global, inter-regional, regional, and local level. Special attention is given to key factors that affect the management and strategies implemented in the logistics of 
INDEPENDENT JOURNAL OF MANAGEMENT \& PRODUCTION (IJM\&P)

http://www.ijmp.jor.br

v. 6, n. 3, July - September 2015

ISSN: 2236-269X

DOI: 10.14807/ijmp.v6i3.294

containers by maritime carriers and other stakeholders in order to better handle these containers. Yeo and Song (2006) empirically identified the competitiveness of container ports in Asia through factors that influence the level of functionality of each port, using a model that analyses the process of moving containers.

From an operational perspective, Hareyama, et al. (1998) proposed a computerized system for container management. This system operates through a device which reads the container's identification code and detects a position for handling. Based on this code and the container position detected, the inventory data of containers stored in the park are updated. Chen, et al. (2007) present a Tabu search algorithm model for tackling the problem of integrated programming of container handling systems in a marine terminal. This model's objective is to minimize the timespan, i.e. the time the operator takes to attend to a given set of vessels. Ottjes, et al. (2007) suggest a multi-terminal simulation system for moving containers. The generic simulation model was constructed by combining three basic functions: transport, transfer, and stacking. It can be used in a variety of subsystems of a container terminal.

Given this scenario, this study proposes the use of a tool called BPM, which allows both perspectives for handling containers, strategic and operational, to be aligned.

\subsection{Business Process Management}

According to the Association of Business Process Management Professionals - (ABPMP), 'Modelling of business processes is a set of activities involved in creating representations of an existing or proposed business process. Modelling business processes provides an end-to-end perspective of primary processes of support and management in an organization' (2009, p. 47).

The purpose of modelling is to create a process image that describes it in a manner sufficient for the task at hand (SUNGAU; NDUNGURU, 2015). Many benefits are provided by process models in the management of business operations, such as understanding of the business process and improving communication by creating a visible representation and commonly shared perspective (LONGARAY, 1997). 'The models are the means to manage the organization's process, analyze process performance, and determine the changes' (ABPMP, 2009, p. 49). 
INDEPENDENT JOURNAL OF MANAGEMENT \& PRODUCTION (IJM\&P)

http://www.ijmp.jor.br

v. 6, n. 3, July - September 2015

ISSN: 2236-269X

DOI: 10.14807/ijmp.v6i3.294

In this sense, process analysis assumes knowledge of the operation under study, which is the first step in establishing an understanding of a current process or creating a new one (FORMENTO; et al., 2013). The BPM CBOK Guide (ABPMP, 2009) proposes an analysis based on some activities that are commonly followed while evaluating processes, including knowledge of the business environment, culture and context of the organization, performance metrics, client interactions, handoffs, business rules, capacity and bottlenecks, variation, costs, human involvement, and process controls.

According to the ABPMP (2009, p. 50), 'there are several modelling, notations, and technical standards currently in use.' 'Many standards and notations have been developed as part of a comprehensive methodology for the improvement of business processes' (p. 51).

In this specific paper, the researchers show the use of Business Process Management modelling as suggested by ABPMP (2009), to redesign the container handling process of a retroportuary terminal.

\section{RESEARCH METHODOLOGY}

This study is based on the methodological framework proposed by Roesch (2010), which is arranged as follows: project purpose, method (design), data collection, and analysis techniques.

As for the project purpose, the research is considered as applied where, according to Roesch (2010, p. 60), 'the source of the research questions is focused on the issues and concerns of the people, and the purpose is to generate potential solutions for human problems'. Hence, this study aims to create a potential solution for the organization under study by redesigning the process of internal handling of refrigerated containers.

With regard to the method used, the research was framed as a case study, as it embodies the various aspects which influence the implementation of the internal handling process of containers in the concerned organization. The organization was founded in 2008 by its subsidiary, a multinational shipping company. The terminal under study is part of a network of empty container storage terminals set up in ports all over the Brazilian coast. Between outsourced services and personnel, the terminal network meets the demand of exporters from most Brazilian states. Its main objective 
INDEPENDENT JOURNAL OF MANAGEMENT \& PRODUCTION (IJM\&P)

http://www.ijmp.jor.br

v. 6, n. 3, July - September 2015

ISSN: 2236-269X

DOI: 10.14807/ijmp.v6i3.294

is to provide support services to its subsidiary via transportation, storage, maintenance, repair, and delivery of container units that meet the standards required by clients, in addition to the international safety standards for cargo transportation.

With regard to the data collection techniques, interviews and direct observation were used to collect the primary data. During the research process, primary qualitative and quantitative data were collected.

The primary qualitative data were extracted from responses in the interviews with those responsible for carrying out the processes under study: the operations manager, the operations coordinator - reefer service, the workshop coordinator, the structural repairs workshop coordinator, and two yard clerks in charge of handling the containers in the terminal yard under study.

The criteria for selecting interviewees were formal connection (presence in the company's organization chart) to the container handling process, a minimum of one year of service, participation in the organization's quality circle, and work on rotating shift schedule.

Each interview took, on average, 60 minutes. They were conducted by two researchers using a semi-structured question script.

A total of 18 interviews were conducted (some of the respondents were interviewed on two occasions and some were interviewed on three occasions, according to the degree of complexity of their involvement in the container handling process).

The primary quantitative data were collected through direct observation, based on the number of movements required for the process steps. This procedure was carried out over a period of 180 days, in different shifts. The routine employed seven researchers. Notes and photographs were taken during the process.

In addition to that, secondary data were collected from the company's computer system, considering the number of units released for export and the number of containers handled by status, with the objective of establishing a representative percentage of each type, and thus being able to estimate the number of movements performed over a certain period of time. 
INDEPENDENT JOURNAL OF MANAGEMENT \& PRODUCTION (IJM\&P)

http://www.ijmp.jor.br

v. 6, n. 3, July - September 2015

ISSN: 2236-269X

DOI: 10.14807/ijmp.v6i3.294

This step was followed by an analysis of documents from the secondary data collection, in order to understand the aspects that influenced the implementation of the container handling process. With regard to the documents, production reports and company oversight spreadsheets relating to the process under study were analyzed.

As for the analytical techniques, a qualitative and quantitative approach was used for the study, with analyses performed by means of descriptive and statistical methods, as well as documentation evaluation.

\section{THE CASE STUDY}

This section describes the case study's steps: mapping of the current process for handling containers (subsection 4.1), analysis of the current process (subsection 4.2), proposed redesign of the process (subsection 4.3), and performance comparison between the current and the proposed process for handling containers (subsection 4.4).

\subsection{Current Process Description}

In the current process, the 'internal handling process of containers' consists of combining all container-related activities carried out in the terminal. By understanding and analyzing the process components, it was found that there are four subprocesses that comprise this process and that each container entering the terminal must undergo these sub-processes. These sub-processes are structural inspection, testing of machinery, structural repairs, and washing.

The aim of this study is to analyze the handling of container units through their sub-processes so as to understand the relationship between them, and to search for optimization opportunities while reducing the handling of container units, as a suggestion for improving the internal handling process of the containers at the terminal under study.

The container is received at the entrance gate, where its specifications are logged into the company's system. Subsequently, the lorry carrying the container enters the courtyard and continues to the inspection sector where a structural inspection is carried out. A form pertaining to the necessary repairs to be made in case of faulty units is also filled out here. At the end of the 'pull' (the transportation of 
INDEPENDENT JOURNAL OF MANAGEMENT \& PRODUCTION (IJM\&P)

http://www.ijmp.jor.br

v. 6, n. 3, July - September 2015

ISSN: 2236-269X

DOI: 10.14807/ijmp.v6i3.294

a container lot from the port to the terminal), these forms are delivered to the gate so that the inspection observations can be entered into the system.

After the completion of the 'pull', the allotted units are moved according to the production capacity to the pre-trip inspection (PTI) test sites, where the cooling machinery is started and inspected, and a report stating the machinery condition is filled out. After the test, if the units' structural and machinery parts are considered acceptable, they are removed for washing, stored in lots, and are made available for delivery. If they require light structural repairs, they are taken to the repair shop, following which they go on to washing, where the process is completed. Only after this cycle is closed are the units placed under 'OK' lots and become usable.

The withdrawal of units from the machine test sites occurs after the tests have been completed. The person responsible for handling the withdrawal of the units checks and records the status of each container in a report according to the status of each unit. These units can be labelled as 'OK', which denotes that the container's refrigeration machinery is operating normally, or 'AV', which states that the unit is damaged beyond repair in terms of allowance value. Damaged units within the cost frame of the repair allowance are repaired during the tests and marked 'OK'.

The next step is to check the status of the structural unit. In order to do this, the yard clerk checks the adhesive labels on the container doors during inspection when the container enters the terminal, indicating whether the unit is 'OK' or has structural damages. Based on this information, he makes the decision as to where to allocate the units according to the different conditions of each container.

The range of possibilities for the unit after the machine testing is summarized within the following machinery and structural status: 'OK/OK', 'OK/AV', 'AV/OK', and 'AVIAV'.

After being tested, 'OK/OK' units may be carried straight to the washing sector, while 'OK/AV' units are carried straight to the workshop for structural repairs. It is mandatory for 'AV/OK' units, however, to be transported to specific lots of units so that, upon authorization from the parent company only, they can be repositioned in the test sites for the necessary repairs. It is mandatory for 'AVIAV' units to be transported to specific lots of units so that, upon authorization from the parent company only, they can be returned to the machine test site and then the structural 
INDEPENDENT JOURNAL OF MANAGEMENT \& PRODUCTION (IJM\&P)

http://www.ijmp.jor.br

v. 6, n. 3, July - September 2015

ISSN: 2236-269X

DOI: 10.14807/ijmp.v6i3.294

repair workshop for the necessary repairs. Figure 01 shows the organization's current container handling process:

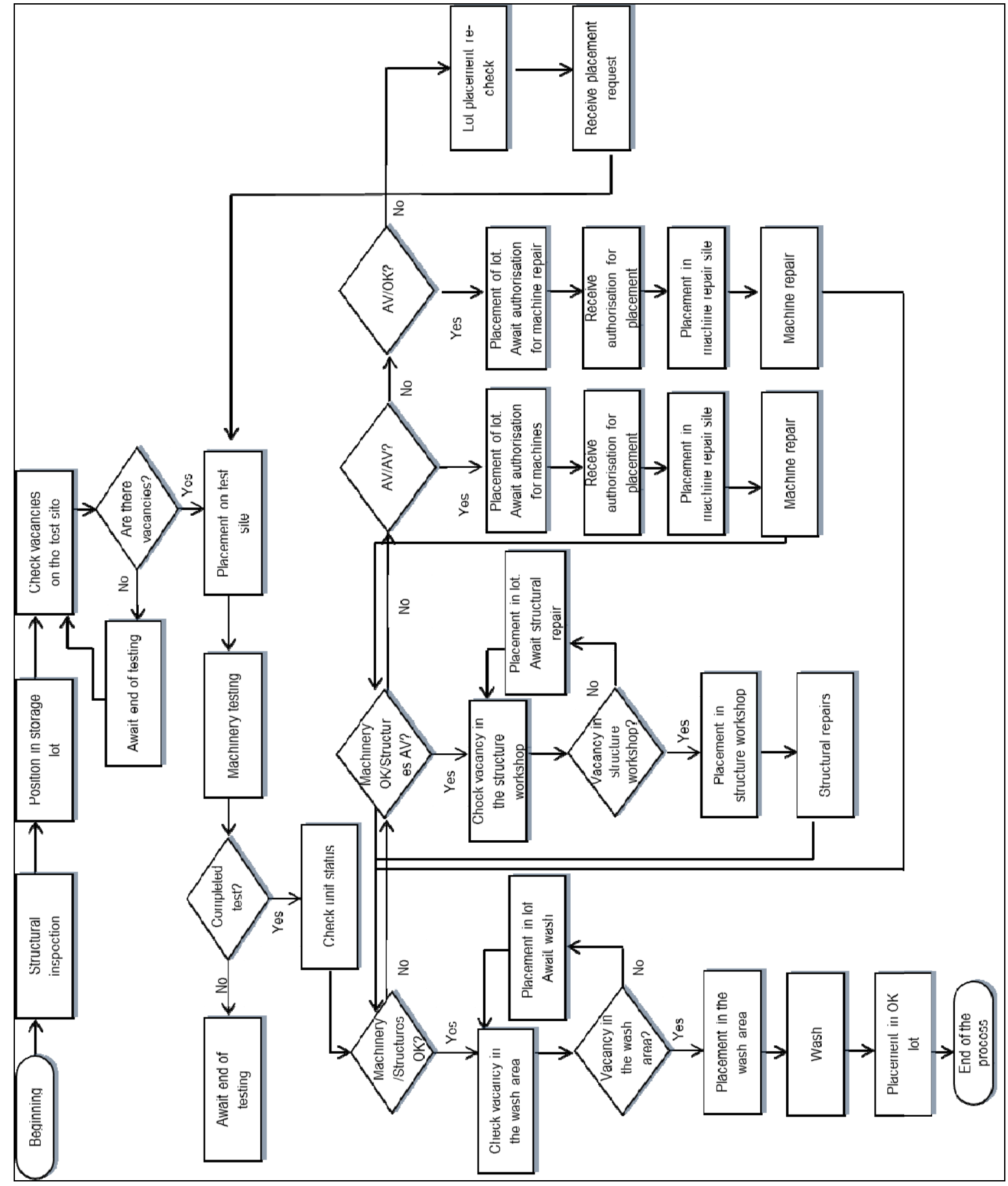

Figure 1: The current 'container handling' process

Source: Authors

\subsection{Current Process Analysis}

The analysis was based on the methodology described in the BPM CBOK GUIDE (2009, v2), Business Process Management - Common Body of Knowledge, where the focus is the search for elements that can show whether or not there exists 
INDEPENDENT JOURNAL OF MANAGEMENT \& PRODUCTION (IJM\&P)

http://www.ijmp.jor.br

v. 6, n. 3, July - September 2015

ISSN: 2236-269X

DOI: 10.14807/ijmp.v6i3.294

the possibility of improvement by reducing the current handling. Other focal points are looking for evidence of any bottlenecks and excessive control transfers (handoffs), as well as performance metrics that may affect the process productivity.

\subsubsection{Operational Bottlenecks}

The operational bottlenecks are divided into two types: unit lots awaiting structural repairs and unit lots awaiting washing.

Unit lots awaiting structural repairs

The placement of units for machine testing without a structural condition restriction results in the placement of mixed units in the test site. Thus, after testing, the faulty units must be placed in lots rather than passing directly to the next process.

Since there is no control over the type of unit being placed on the test site, the structural repair fails to enable the control of the placement for the next step, which is the structural repair workshop.

Unit lots awaiting washing

According to the interviews, as far as the problem of creating lots awaiting washing is concerned, it was confirmed that the main reasons for their creation are the unavailability of forklifts as they are needed for other services, the high number of container withdrawals for the maintenance of daily production, and the low production capacity due to space constraints for the placement of the units.

\subsubsection{Control Transfers (Handoffs)}

According to the BPM CBOK Guide (2009, p. 86), a handoff is 'any point in a process where the work or information passes from one system to another person or group'. The process model of the company is based on a linear sequence, in which each sub-process can only be performed after the completion of the previous subprocess and after transferring one container unit to another, because the sectors in charge of this performance are located at different points.

This model does not allow for the possibility of implementing integrated services. Also, the need for transfers and the creation of lots between sectors eventually leads to an excessive number of control transfers. This can result in difficulties in identifying problems, delays or errors, as well as faulty units delivered to clients and lengthy storage in the wait lots. 
INDEPENDENT JOURNAL OF MANAGEMENT \& PRODUCTION (IJM\&P)

http://www.ijmp.jor.br

v. 6, n. 3, July - September 2015

ISSN: 2236-269X

DOI: 10.14807/ijmp.v6i3.294

\subsubsection{Performance Metrics}

During the research process, data pertaining to each of the sub processes that make up the maintenance process and repair of refrigerated containers in the company, as well as the monthly demand for this type of container delivered to clients were obtained for the first half of 2014. The data also included monthly machine testing figures, number of structural repairs, number of washes, and number of export clearances. Table 1 shows the quantities produced in each sector and the demand in the period:

Table 1: Production and Demand

\begin{tabular}{|c|c|c|c|c|c|c|c|c|}
\hline $\mathbf{2 0 1 4}$ & JAN & FEB & MAR & APR & MAY & JUN & TOTAL & AVERAGE \\
\hline MACHINE TESTING & 808 & 644 & 664 & 798 & 498 & 542 & 3,954 & 659 \\
\hline STRUCTURAL REPAIRS & 451 & 362 & 323 & 376 & 217 & 224 & 1,953 & 326 \\
\hline WASH & 727 & 620 & 598 & 741 & 548 & 514 & 3,748 & 625 \\
\hline EXPORT CLEARANCE & 641 & 643 & 714 & 594 & 545 & 692 & 3,829 & 638 \\
\hline
\end{tabular}

Source: Data supplied by the organization

By interpreting the data and information gathered, it was concluded that there is actually a difference in productivity between sectors in the organization. It was observed that there is a deficit in productivity when connecting the first phase of production (machine testing) with the following phases, which are the sub processes of structural repair and cleaning. Both fail to meet the quantities available to their sectors, leading to the need for the formation of wait lots, and thereby increasing the number of required withdrawals to perform the entire process.

The main problem of production in the structural repair workshop was the impossibility of production planning as a result of not separating the structurally damaged units at the beginning of the process. Another perceived factor was the fact that the workshop serviced all types of units in the terminal by the workshop, and as a result, the repair of refrigerated units was sometimes set aside to perform repairs on other types of containers.

As for the washing sector, a factor leading to the creation of waiting lots and resulting in an increase in movement of containers was space restriction. At least one pile positioned for washing should be changed daily to maintain productivity; else, idleness and decreased production may ensue. Another harmful factor was the unavailability of machinery for withdrawals, which were sometimes displaced to meet other demands at the terminal. 
INDEPENDENT JOURNAL OF MANAGEMENT \& PRODUCTION (IJM\&P)

http://www.ijmp.jor.br

v. 6, n. 3, July - September 2015

ISSN: 2236-269X

DOI: 10.14807/ijmp.v6i3.294

\subsection{The Processes Proposal}

With the information obtained, alternatives were considered to reduce handling by removing the process wait lots.

Attempts to organize activities in search of a solution to the problem of the wait lots was not successful, and it was observed that the biggest problem was not the lots, but the structure of the current process due to its division into three performance sectors and linear implementation. According to Hammer and Champy (1993, p. 40), 'the linear sequence of the tasks imposes an artificial precedence that slows down the work'.

The explanation of the ideas presented in an attempt to reorganize the process tasks were easily proven to be inefficient when faced with the problems encountered in the analysis of the current process, justifying the need to design a new process for the organization, focusing on improving productivity by reducing the number of internal handlings.

The proposal takes into account the replacement of the current process with two separate processes: one for the units arriving at the terminal with an OK structure and one for units arriving at the terminal with a defective structure-but both with the combination of services at a single point.

\subsubsection{The first process proposal - OK containers}

In the first process, structural part units with the OK status should be allocated at a test site equipped with washing machines and a structure for the collection of wastewater from the sub process.

The formation of the new process proposed is outlined in figure 2 and was created by the researcher to provide a better view in a simplified model. With integrated washing machines and testing services, the process will have only one possible handling. The containers will be placed at a site, facing each other, and the services will be executed simultaneously.

While tests are being conducted on the lots on one side, washing can be initiated for the lots on the other side. In this manner, by the end of testing, the 
INDEPENDENT JOURNAL OF MANAGEMENT \& PRODUCTION (IJM\&P)

http://www.ijmp.jor.br

v. 6, n. 3, July - September 2015

ISSN: 2236-269X

DOI: 10.14807/ijmp.v6i3.294

services will be reversed-with tests being performed on the already-washed units and the units already tested being washed.

This process will be responsible for collecting OK-structure units that should have been separated by the yard clerk after a structural inspection, putting out the OK/OK and AV/OK units pertaining to machinery and structure, respectively.

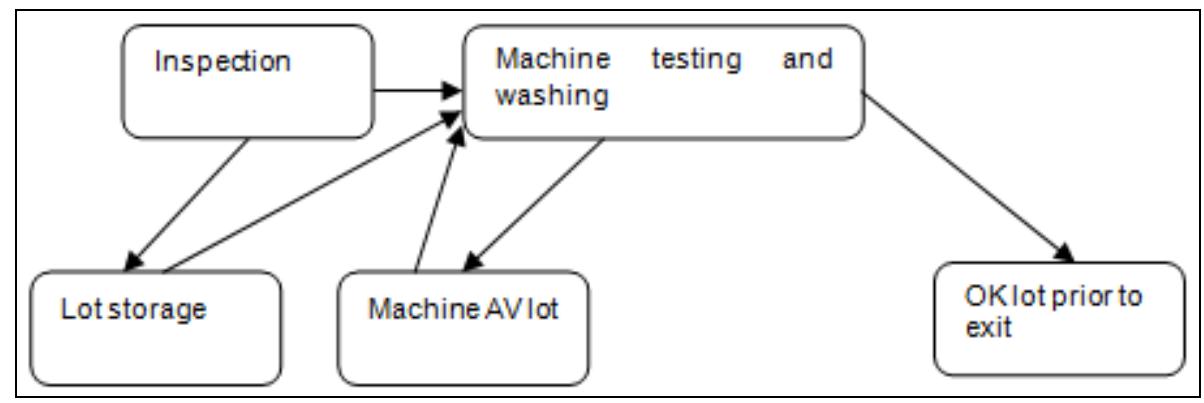

Figure 2: Handling Flowchart of the First New Process of Proposal Source: Authors

The handling sequence and the number of withdrawals in this process are described as follows:

Handling possibility for OK/OK units $\rightarrow$ Withdrawal 1 - from inspection to the storage lot; Withdrawal 2 - from the storage lot to the test site/wash; and Withdrawal 3 - from the test site/wash to the export lot

Handling possibility for AV/OK units $\rightarrow$ Withdrawal 1 - from inspection to the storage lot; Withdrawal 2 - from the storage lot to the test site/wash; Withdrawal 3 - from the test site/wash to the lot awaiting machine repair authorization; Withdrawal 4 - from the lot awaiting machine repair authorization to the test site/wash; and Withdrawal 5 from the test site/wash to the export lot.

In this proposal, the containers will then need to be separated upon arrival, creating separate lots for OK structural parts and faulty units. Thus, the units allocated to lots with OK structural parts will enter production in this model and be placed at the test and wash sites.

After the sub processes, OK test units will be moved directly to the unit lots ready for delivery and faulty units will be allocated in lots awaiting approval from the head office for the repairs to be done. Once cleared, they will return to the test and wash site for repairs, being subsequently moved to the unit lots ready for withdrawal by the customers. 
INDEPENDENT JOURNAL OF MANAGEMENT \& PRODUCTION (IJM\&P)

http://www.ijmp.jor.br

v. 6, n. 3, July - September 2015

ISSN: 2236-269X

DOI: 10.14807/ijmp.v6i3.294

The new first process proposal was designed, as shown in figure 3:



Figure 3: Flowchart Showing the First New Process of Proposal Source: Authors

\subsubsection{The second process proposal - damaged containers}

The second part of the proposal is based on the same logic: the integration of services at a single point. Here, the services will be moved to a second area, which the author refers to as the services site, where the testing sub processes, wash, and structural repairs can be performed at a single place. The site should be located next to the first site to make use of the power grid and wastewater treatment for the two sub processes, minimizing the cost of building a new structure.

The structurally damaged units separated in the lots after the arrival inspection should be placed on this site. This process will require the allocation of a structural repair workshop team to exclusively service these refrigerated units. Hence, all maintenance and repair processes will be assigned to a single sector (the reefer service), thereby eliminating the problem found in the structural repair workshop where, because of the need to deal with other types of containers, the refrigerated 
INDEPENDENT JOURNAL OF MANAGEMENT \& PRODUCTION (IJM\&P)

http://www.ijmp.jor.br

v. 6, n. 3, July - September 2015

ISSN: 2236-269X

DOI: 10.14807/ijmp.v6i3.294

units end up awaiting repair longer than necessary, leading to a loss in productivity and the formation of wait lots. The formation of the second proposed process is shown in figure 4.

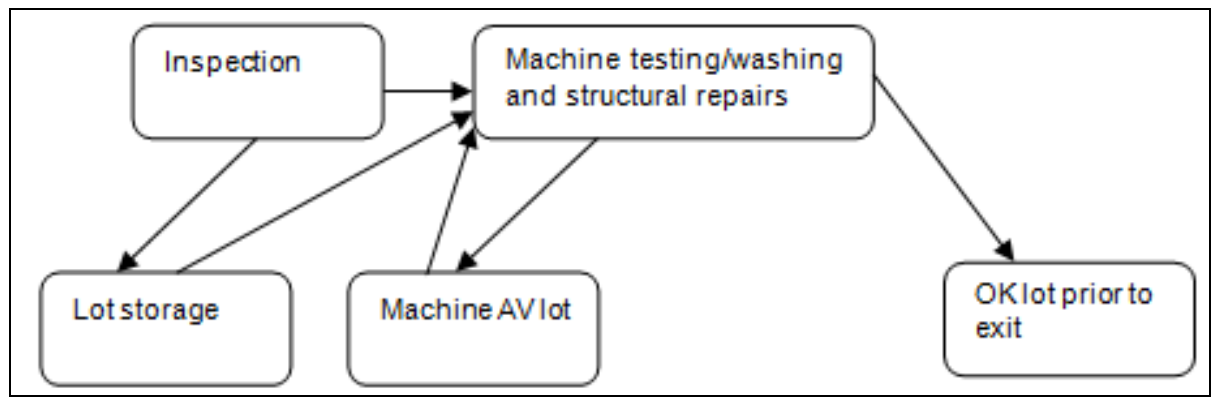

Figure 4: Handling Flowchart of the Second New Process of Proposal

Source: Authors

The units will be allocated to areas containing a structure for the implementation of machine testing, washing, and structural repairs. Once positioned, the structural repairs can be initiated immediately, while washing can simultaneously be initiated on the other units, which will already be positioned, and then the tasks can be inverted once the sub processes intersect. In this manner, the repaired units can then be washed and the washed units can be repaired. As the repairs and washes are completed, the units can be linked for test placement to complete the maintenance and repair process.

This process will be responsible for collecting structurally damaged units that should have been separated by the yard clerk after the structural inspection. The outputs will then be OK/OK, OK/AV, and AVIAV machine and structural units, respectively.

The handling sequence and the number of withdrawals in the second process proposal are described as follows:

Handling possibility for OK/OK units $\rightarrow$ Withdrawal 1 - from inspection to the storage lot; Withdrawal 2 - from the storage lot to the services site; and Withdrawal 3 - from the services site to the export lots

Handling possibility for OK/AV and AVIAV units $\rightarrow$ Withdrawal 1 - from inspection to the storage lot; Withdrawal 2 - from the storage lot to the services site; Withdrawal 3 from the services site to the lot awaiting structural repair authorization; Withdrawal 4 from the lot awaiting structural repair authorization to the services site; and Withdrawal 5 - from the services site to the export lots. 
INDEPENDENT JOURNAL OF MANAGEMENT \& PRODUCTION (IJM\&P)

http://www.ijmp.jor.br

v. 6, n. 3, July - September 2015

ISSN: 2236-269X

DOI: 10.14807/ijmp.v6i3.294

Figure 5 shows the process for structurally damaged units separated at the beginning of the process.

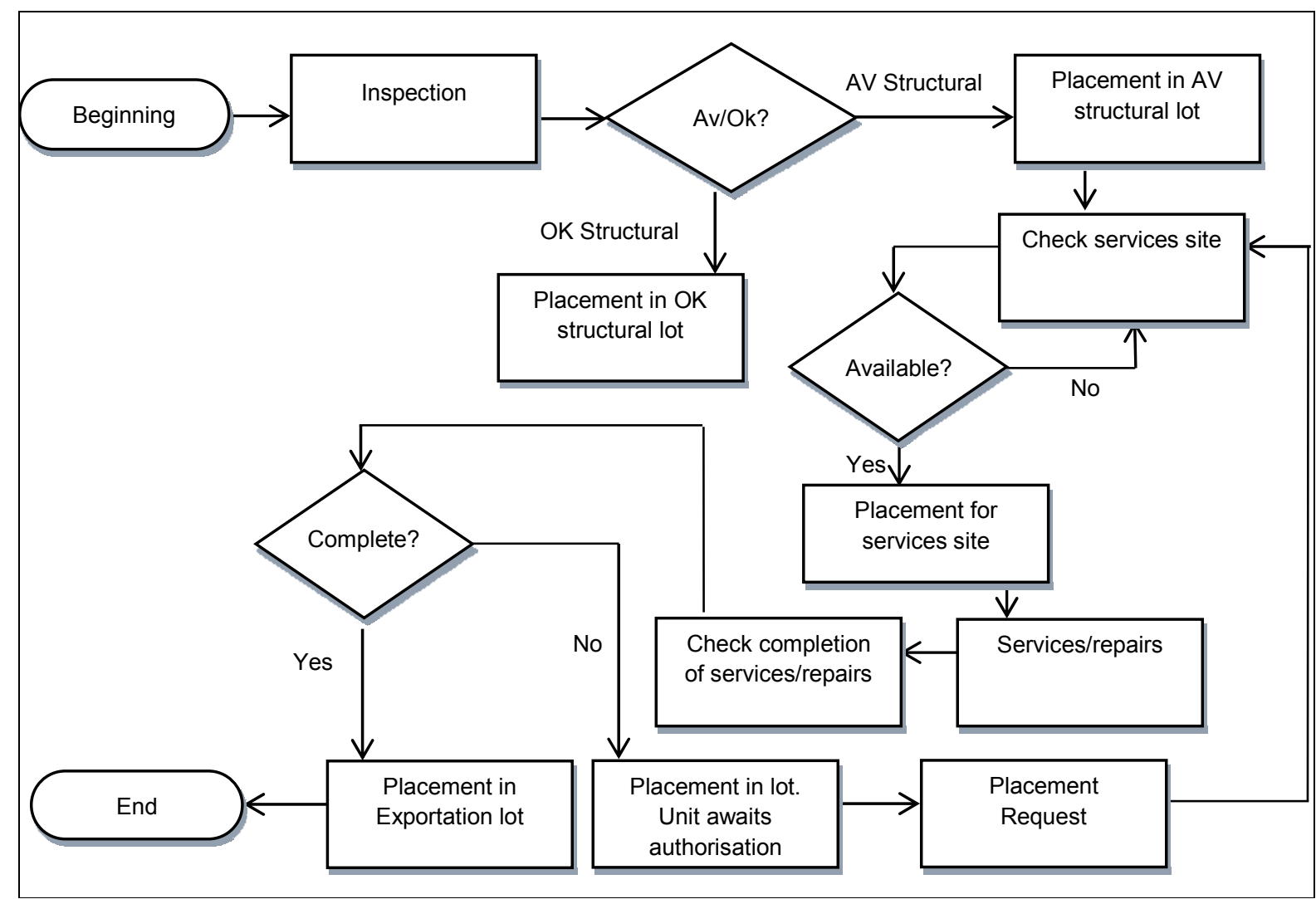

Figure 5: Flowchart Showing the Second Process of Proposal Source: Authors

\subsection{Comparison between the current process and the proposal processes}

Taking into account the number of containers cleared for export in the concerned period and the representation of the units put into production, and the withdrawal of 756 units checked, the approximate number of withdrawals in the period was calculated.

Table 2 is a representative table based on the 756 containers checked, with unit values of $42 \%$ OK/OK, $51 \%$ OK/AV, $2 \%$ AV/OK, and $5 \%$ AVIAV.

Table 2 - Status Type Representation

\begin{tabular}{|c|c|c|c|c|c|c|}
\hline STATUS & OK STRUCTURE & AV STRUCTURE & OK/OK & OK/AV & $\mathrm{AV} / \mathrm{OK}$ & AVIAV \\
\hline OK MACHINERY & 318 & 386 & $42 \%$ & $51 \%$ & $2 \%$ & $5 \%$ \\
\hline AV MACHINERY & 12 & 40 & & & & \\
\hline TOTAL & \multicolumn{2}{|c|}{$\frac{1}{756}$} & & & & \\
\hline
\end{tabular}

Source: Data supplied by the organization 
INDEPENDENT JOURNAL OF MANAGEMENT \& PRODUCTION (IJM\&P)

http://www.ijmp.jor.br

v. 6, n. 3, July - September 2015

ISSN: 2236-269X

DOI: 10.14807/ijmp.v6i3.294

The representation gathered in the verification above was applied to the demand of the period, resulting in the values shown in Table 3.

Table 3 - Representation Applied to Demand

\begin{tabular}{|c|c|c|c|c|c|c|}
\hline STATUS & OK STRUCTURE & AV STRUCTURE & OK/OK & OK/AV & $\mathrm{AV} / \mathrm{OK}$ & AVIAV \\
\hline OK MACHINERY & 1,608 & 1,952 & $42 \%$ & $51 \%$ & $2 \%$ & $5 \%$ \\
\hline AV MACHINERY & 78 & 191 & & & & \\
\hline TOTAL & \multicolumn{2}{|c|}{$\frac{1}{3,829}$} & & & & \\
\hline
\end{tabular}

Source: Data supplied by the organization

The representation of each status was applied to the demand of the period, resulting in the figures shown in table 4: 1,608 OK/OK units, 1,952 OK/AV units, 78 AV/OK units, and 191 AVIAV units, pertaining to machinery and structure.

Table 4 - Number of Handlings in the Current Process

\begin{tabular}{|l|c|c|c|c|}
\hline & OK/OK & OK/AV & AV/OK & AV/AV \\
\hline AVERAGE HANDLINGS IN THE CURRENT PROCESS & 4.5 & 6 & 6.5 & 8 \\
\hline PRODUCTION TOTAL (APPROX.) & 1,608 & 1,952 & 77 & 18 \\
\hline TOTAL HANDLINGS (APPROX.) & 7,236 & 11,712 & 500 & 144 \\
\cline { 1 - 2 } GENERAL TOTAL WITHDRAWALS (APPROX.) & 19,592 & \multicolumn{3}{|l}{} \\
\cline { 1 - 2 } PERIOD DEMAND & 3,829 & &
\end{tabular}

Source: Data supplied by the organization

These numbers were, in turn, applied to the approximate handling table created while mapping the processes, where the average number of handlings for each status was obtained to form the basis for the total number of handlings.

Based on these data, the average number of 19,952 withdrawals was calculated for the 3,829 containers cleared in the period. The same criteria was used for the proposed processes, reaching the approximate number of 11,155 withdrawals for the same 3,829 containers cleared in the period, as shown in the table 5.

Table 5 - Number of Movements in the Proposed Process

\begin{tabular}{|l|c|c|c|c|}
\hline & OK/OK & OK/AV & AV/OK & AV/AV \\
\hline AVERAGE HANDLINGS OF THE PROCESS & 3 & 3 & 5 & 5 \\
\hline TOTAL PRODUCTION PER STATUS (APPROX) & 1,608 & 1,952 & 77 & 18 \\
\cline { 1 - 2 } TOTAL HANDLINGS PER STATUS (APPROX.) & 4,824 & 5,856 & 385 & 90 \\
\cline { 1 - 2 } TOTAL WITHDRAWALS OVERALL (APPROX.) & 11,155 & \multicolumn{3}{|l}{} \\
\cline { 1 - 2 } PERIOD DEMAND & 3,829 & &
\end{tabular}

Source: Data supplied by the organization 
INDEPENDENT JOURNAL OF MANAGEMENT \& PRODUCTION (IJM\&P)

http://www.ijmp.jor.br

v. 6, n. 3, July - September 2015

ISSN: 2236-269X

DOI: 10.14807/ijmp.v6i3.294

By comparing the current and proposed models, the possibility of reducing handlings by approximately 44\% was observed, with 19,952 handlings in the current process and 11,155 in the proposed model.

The numbers confirmed what was expected. The application of process design principles followed in the study brought about the actual possibility of a considerable reduction in the number of container handlings, thus proving the possibility of improving the process currently followed in the organization.

\section{SUMMARY}

This study aimed to achieve the reduction of the internal handling of refrigerated containers within the organization through the use of process management techniques. Based on the results, it can be concluded that this goal was achieved.

The mapping of the process used allowed for an understanding of the activity flow, how the activities are deployed, and the inputs and results of the sub-processes they comprise. Thus, it was possible to account for the various types of container handlings used in the system. With an overall understanding of these handlings, mapping the different existing flows was made possible, thereby leading to an understanding of all the combinations that the process allows.

Using the map pertaining to the current process, the formation of wait lots was evident between the structural repair and container wash phases, which indicated potential bottlenecks in the process. The main factors were found to be the lack of separation between the structurally damaged units and the OK units at the initial storage phase, making it impossible to control the placement of the container types put into production; the care of various types of containers in the same workshop, sometimes leading to the servicing of one container type over another; the unavailability of machines to remove units; and finally, the limited space for meeting the demand at the wash site. These were seen as the causative factors for the creation of the above-mentioned wait lots, leading to the existence of operational bottlenecks. The excess of control transfers for the units during their passage through the process was also seen as a determining factor leading to problems such as the failure to perform tasks. 
INDEPENDENT JOURNAL OF MANAGEMENT \& PRODUCTION (IJM\&P)

http://www.ijmp.jor.br

v. 6, n. 3, July - September 2015

ISSN: 2236-269X

DOI: 10.14807/ijmp.v6i3.294

For this purpose, two processes were created: one for units with OK structure status and one for units with faulty structures. The new processes were mapped out and designed using the same methodology used for mapping the BPM CBOK Guide processes.

After completing the current and proposed processes, the approximate number of withdrawals of each unit was calculated based on the demand of the period analyzed in the research process, showing a considerable $43 \%$ reduction in container handling in the proposed process compared to the current process.

With these results, it could be observed that the analysis of process design can provide organizations with the possibility of major improvements, which can have a positive impact on the organization due to leaner processes.

With regard to this work's limitations, the case study's uniqueness can be highlighted. Since the research refers to a specific organization, in a particular economic and social sector, it does not allow for generalizations to be made based on this study.

As for the recommendations for future work, the suggestion is to analyze other processes in the company under study. From another perspective, it would be interesting to replicate the case study in companies working in other segments of the port industry.

\section{ACKNOWLEDGMENT}

The authors thank Editage for translating the text to English, the anonymous reviewers for their important contributions to the work, and CNPq for funding the research.

\section{REFERENCES}

ABPMP. (2009). Guide to the Business Process Management Body of Knowledge - (BPM CBOK GUIDE), ABPMP, Minnesota.

CHEN, L.; BOSTEL, N.; DEJAX, P.; CAI, J.; XI, L. (2007). A tabu search algorithm for the integrated scheduling problem of container handling systems in a maritime terminal. European Journal of Operational Research, v. 181, p. 40-58.

FORMENTO, H.; CHIODI, F.; CUSOLITO, F.; ALTUBE, L.; GATTI S. (2013). Key factors for a continuous improvement process. Independent Journal of Management \& Production (IJM\&P). v. 4, n. 2, p. 391-415. DOI: 10.14807/ijmp.v4i2.76. 
INDEPENDENT JOURNAL OF MANAGEMENT \& PRODUCTION (IJM\&P)

http://www.ijmp.jor.br

v. 6, n. 3, July - September 2015

ISSN: 2236-269X

DOI: 10.14807/ijmp.v6i3.294

HAMMER, M.; CHAMPY, J. A. (1993) Reengineering the Corporation: A Manifesto for Business Revolution, Harper Business Books, New York.

HAREYAMA, S.; SERIZAWA, T.; HAMADA, H.; BAN, T. (1998). Container handling apparatus and management system. USA Patents, $n^{\circ}$ 5.780.826, Jul., 14, p. 1-14.

LONGARAY, A. Reengenharia de Processos: os casos da Tintas Renner S.A. e do Grupo Gerdau. 1997. 128f. Dissertação (Mestrado em Administração) Universidade Federal de Santa Catarina - UFSC, Florianópolis, 1997.

NOTTEBOOM, T. (2002). Consolidation and contestability in the European container handling industry. Maritime Policy \& Management: The flagship journal of international shipping and port research, v. 29, n.3, 257-269.

OTTJES, J.; VEEKE, H.; DUINKERKEN, M.; RIJSENBRIJ, J.; LODEWIJKS, G. (2007). Simulation of a multiterminal system for container handling. Container Terminals and Cargo Systems. Springer, p. 15-36.

ROESCH, S. M. A. (2010). Projetos de estágio e de pesquisa em administração. São Paulo: Atlas.

STAHLBOCK, R.; VOß (2008). Operations research at container terminals: a literature update. OR Spectrum, v. 30, p. 1-52.

SUNGAU, J.; NDUNGURU, P. (2015). Business process re-engineering: a panacea for reducing operational cost in service organizations. Independent Journal of Management \& Production (IJM\&P), v. 6, n. 1, January-March, p. 141-168. DOI: 10.14807/ijmp.v6i1.248.

THEOFANIS, S.; BOILE, M. (2009). Empty marine container logistics: facts, issues and management strategies. GeoJournal, v. 74, n. 1, p. 51-65.

YEO, G.; SONG, D. (2006). An application of the hierarchical fuzzy process to container port competition: policy and strategic implications. Transportation, v. 33, n. 4 , p. 409-422.

VACCA, I.; SALANI, M.; BIER LAIRE, M. (2010). Optimization of operations in container terminals: hierarchical vs integrated approaches. Transp-OR, STRC 2010, p. 1-15. 